\title{
On the syntactically complex status of negative indefinites
}

\author{
Hedde Zeijlstra
}

Received: 21 December 2007 / Accepted: 29 March 2010/Published online: 7 June 2011

(C) The Author(s) 2011. This article is published with open access at Springerlink.com

\begin{abstract}
Negative Indefinites (NIs) in languages such as Dutch and German may give rise to split-scope readings. Sentences like German Du must keine Krawatte anziehen ('you must wear no tie') have a reading where the modal takes scope in between the negation and the indefinite. In this paper I argue that West Germanic NIs are not negative quantifiers (in the Montegovian sense), but complex syntactic structures that consist of an abstract negative operator and an indefinite that are spelled out as a single word. Split-scope effects result from application of the copy theory of movement. I argue that in split-scope constructions, though they are spelled out as a single word, after Quantifier Raising the negative operator is interpreted in a higher copy and the indefinite in a lower copy of the NI. Furthermore I demonstrate that alternative analyses that take NIs in Dutch and German to be negative quantifiers, n-words, or the result of amalgamation or incorporation processes face problems that the analysis presented in this paper does not encounter.
\end{abstract}

Keywords Negation $\cdot$ Indefinites $\cdot$ Split-scope $\cdot$ Negative quantifiers $\cdot$

Negative concord

\section{Introduction}

Negative Indefinites (NIs), such as English nobody, nothing, or no body, are generally considered to be generalized quantifiers that are semantically negative:

$$
\begin{aligned}
& \text { (1) } \llbracket \text { nobody } \rrbracket=\lambda P . \neg \exists x[\operatorname{body}(x) \& P(x)] \\
& \text { or equivalently } \\
& \llbracket \text { nobody }=\lambda \mathrm{P} . \forall \mathrm{x}\left[\operatorname{body}{ }^{\prime}(\mathrm{x}) \rightarrow \neg \mathrm{P}(\mathrm{x})\right]
\end{aligned}
$$

However, the question as to whether NIs in languages such as Dutch, German and English should be regarded as negative quantifiers has been challenged by examples such as (2), which appear to be problematic for analyses of NIs in terms of negative quantifiers.

\footnotetext{
H. Zeijlstra $(\bowtie)$

Amsterdam Center for Language and Communication, University of Amsterdam, Spuistraat 134 (cg NTK), 1012 VB Amsterdam, The Netherlands

e-mail: Zeijlstra@uva.nl
} 
(2) Du musst keine Krawatte anziehen.

German $^{1}$

You must no tie wear

a. 'It is not required that you wear a tie.'

b. 'There is no tie that you are required to wear.'

$\neg>$ must $>\exists$

c. 'It is required that you don't wear a tie.'

$\neg>\exists>$ must

must $>\neg>\exists$

In (2) the most salient reading is the so-called split-scope reading in (2a) where the negation outscopes the modal auxiliary, which in turn outscopes the indefinite. Note that readings where the entire NI has wide or narrow scope with respect to the modal verb are also available $(2 \mathrm{~b}-\mathrm{c})$.

Split-scope readings form a serious problem for a treatment of NIs in terms of negative quantifiers, as the negation associated to the NI and the indefinite part are allowed to take scope from different clausal positions. In a recent and influential thesis Penka (2007) has argued for a universal treatment of NIs: all NIs are semantically nonnegative indefinites, just as Ladusaw (1992) and Zeijlstra (2004, 2008) have argued for n-words (as NIs in Negative Concord languages are standardly referred to); the only difference then between n-words and NIs in Double Negation languages is that the former may be licensed under multiple agreement (i.e., one (possibly covert) semantic negation may license multiple n-words), whereas the latter may only be licensed under single agreement (every NI must be licensed by a unique licenser).

Penka's analysis runs counter to previous analyses that have been proposed in the literature. The first approach takes split-scope effects to result from lexical decomposition by means of some process of amalgamation (Jacobs 1980) or incorporation (Rullmann 1995). The second approach takes NIs to be plain negative quantifiers and derives split-scope readings as an entailment of quantification over kinds (Geurts 1996) or properties (De Swart 2000).

In this paper, however, I argue that both Geurts' and De Swart's approach that takes NIs to be negative quantifiers and Penka's approach that takes n-words to be semantically non-negative in all languages face serious problems. I also point out several problems for the amalgamation/incorporation approaches, but I argue that these problems can easily be overcome once it is adopted that that NIs in Double Negation languages are the single spell-out of a piece of syntactic structure that consist of two different objects: a negative operator and an indefinite. Under this analysis the meaning of an NI in most cases is equivalent to the meaning of a negative quantifier, but this analysis accounts for split-scope interpretations as well as a result of partial reconstruction following after Quantifier Raising (QR) of NIs.

The paper thus concludes that split-scope readings can only be accounted for in terms of decomposition of NIs and not in terms of plain negative quantifiers or n-words.

The paper is organized as follows: After introducing the relevant data in the next section, I present my analysis of NIs and apply it to the problematic cases. This analysis is then compared to previous accounts (section 4). In this section I demonstrate that analyses that take NIs to be negative quantifiers face serious problems, as do analyses that take NIs in Dutch and German to be n-words, not much different from n-words in Negative Concord languages, face serious problems. Section 5, finally, concludes.

\footnotetext{
${ }^{1}$ Unless mentioned otherwise, the German data are all taken from Penka and Zeijlstra (2005).
} 


\section{Data}

In this section I discuss a phenomenon occurring in West Germanic languages that challenges the view that NIs in these languages are negative quantifiers. This phenomenon was first noted in Bech (1955/57) and later discussed, among others, in Jacobs (1980) for German and Rullmann (1995) for Dutch. It is sometimes referred to as scope-splitting, since semantically the negation and the indefinite meaning component of NIs take scope independently of each other. This can be seen in environments where the negation takes wide scope over some particular operator, while the indefinite meaning component has narrow scope. A split-scope reading is generally available for NIs embedded under modal or object intensional verbs and with NIs in idiomatic expressions.

\subsection{Modal verbs}

Consider again the German example given in (2), in which an NI is embedded under a modal verb:

(3) Du musst keine Krawatte anziehen.

German

You must no tie wear

a. 'It is not required that you wear a tie.'

$\neg>$ must $>\exists$

b. 'There is no tie that you are required to wear.'

$\neg>\exists>$ must

c. 'It is required that you don't wear a tie.'

must $>\neg>\exists$

The most salient reading of this sentence is paraphrased in (3a). As can be read off from this paraphrase, negation has wide scope over the modal, whereas the indefinite has narrow scope. This reading, however, cannot be derived under the assumption that the NI keine Krawatte is a plain negative quantifier. The only readings the negative quantifier analysis derives are the ones paraphrased in (3b) and (3c). In (3c), the NI is interpreted with surface scope, and both the negation and the indefinite have narrow scope with respect to the modal. This reading, equivalent to 'you are not allowed to wear a tie', is hard to get, and available only with lots of help from the context, because there is a strong tendency in German for negation to outscope modals (see De Haan 1997). The only way the modal can end up in the scope of the negation is by LF-movement of the negative quantifier across the modal, resulting in reading (3b), in which both the negation and the indefinite outscope the modal. But the wide-scope reading has very weak truth conditions: (3b) is true if there is no specific tie that you are required to wear. This does not exclude the possibility that the occasion under discussion might require that you wear some tie or other. This is contrary to intuitions, according to which the sentence in (3) denies that wearing ties is obligatory. The same line of argumentation carries over to the following Dutch example (from Rullmann 1995: 194):

(4) Ze mogen geen verpleegkundige ontslaan.

Dutch

They may no nurse fire

a. 'They are not allowed to fire any nurse.'

$\neg>$ may $>\exists$

b. 'There is no nurse who they are allowed to fire.'

$\neg>\exists>$ may

c. 'They are allowed not to fire a nurse.'

may $>\neg>\exists$ 
The case for the split-scope reading can be made even stronger. In the context of expletive es 'there' an indefinite embedded under a modal can only take narrow scope:

(5) Es muss ein Arzt anwesend sein.

German

There must a physician present be

a. 'It is required that there be a physician present.' must $>\exists$

b. *'There is a physician who is required to be present.' $\quad \exists>$ must

Similarly, an NI embedded under a modal in a there-insertion context cannot take scope above the modal. But in the most salient reading, the negation nevertheless outscopes the modal.

(6) Es muss kein Arzt anwesend sein.

German

There must no physician present be

a. 'It is not required that there be a physician present.'

$\neg>$ must $>\exists$

b. *'There is no physician who is required to be present.'

$\neg>\exists>$ must

c. 'It is required that there be no physician present.'

must $>\neg>\exists$

And the case can be made even stronger still; if (6) contains a modal verb that is a Negative Polarity Item, which therefore requires narrow scope with respect to negation, the split-scope reading is the only available one, as shown below:

(7) Es braucht kein Arzt anwesend zu sein.

German

There needs no physician present to be

a. 'It is not required that there be a physician present.' $\quad \neg>$ need $>\exists$

b. *'There is no physician who is required to be present.'

$\neg>\exists>$ need

c. * 'It is required that there be no physician present.'

need $>\neg>\exists$

These considerations show that the salient reading cannot somehow be derived from the wide- or narrow-scope reading of a negative quantifier, thereby confirming that scope splitting of NIs is real.

Most of the literature on split-scope readings focuses on Dutch and German, but split-scope readings are not restricted to these languages. English NIs also exhibit split-scope readings under modals, although things look slightly different, since English modals have different and generally speaking more fixed interpretational scopal restrictions with respect to negation. As described by Iatridou and Sichel (2010) English must, for instance, must always outscope negation; thus under must no split-scope readings arise:

(8) You must do no homework.

a. 'It is required that you do no homework.'

must $>\neg>\exists$

b. *'It is not required that you do homework.'

$\neg>$ must $>\exists$

c. *'There is no homework that you are required to do.'

$\neg>\exists>$ must

Have to, however, normally scopes under negation. And indeed, when have to is combined with an NI, split-scope effects show up. Sentence (9) is clearly ambiguous 
between a split-scope and a non-split-scope reading (data from Iatridou and Sichel 2010); only the reading where the modal outscopes negation is ruled out:

(9) You have to do no homework.
a. *'It is required that you do no homework.'
must $>\neg>\exists^{2}$
b. 'It is not required that you do homework.'
$\neg>$ must $>\exists$
c. 'There is no homework that you are required to do.'
$\neg>\exists>$ must

English thus in principle also allows split-scope readings in a manner similar to Dutch and German: the only reason why not all English modal auxiliaries may give rise to those readings is that they are blocked due to independent properties of modal auxiliaries.

\subsection{Object intensional verbs}

Scope splitting also occurs when an NI is the object of a transitive intensional verb like seek, need, or owe, as demonstrated in the following examples for German, Dutch, and English, respectively.

(10) Perikles schuldet Socrates kein Pferd.

German

Perikles owes Socrates no horse

a. 'Perikles is not obliged to give Socrates a horse.' $\quad \neg>$ owe $>\exists$

b. 'There is no horse that P. is obliged to give to Socrates.' $\neg>\exists>$ owe

c. *'Perikles is obliged not to give Socrates a horse.' owe $>\neg>\exists$

(11) Hans zoekt geen eenhoorn.

Dutch

Hans seeks no unicorn

a. 'Hans is not trying to find a unicorn.'

$\neg>$ seek $>\exists$

b. 'There is no unicorn Hans is trying to find.'

$\neg>\exists>$ seek

c. *'Hans is trying not to find a unicorn.'

seek $>\neg>\exists$

(12) Mary needs no secretary.

a. 'It is not the case that Mary needs a secretary.' $\quad \neg>$ need $>\exists$

b. 'There is no secretary that Mary needs.'

$\neg>\exists>$ need

c. *'What Mary needs is no secretary.'

need $>\neg>\exists$

As before, the split-scope reading (a) is the salient one. Under intensional verbs, the narrow-scope reading (c) is never available at all. Note that while the wide-scope reading (b) is possible, it has very weak truth conditions. (11b), for instance, is true if unicorns do not exist in the evaluation world, independently of Hans' activities.

\subsection{Idiomatic expressions}

Finally, German, Dutch, and English idioms involving an indefinite are generally negated by replacing the indefinite with an NI. The negation then applies to the idiom as such (see (13)-(14)).

\footnotetext{
$\overline{{ }^{2} \text { In certain contexts, for certain }}$ speakers this reading is available as well (cf. Iatridou and Sichel 2010).
} 
(13) a. Hans hat mir einen Bären aufgebunden.

German

Hans has me a bear up-tied

'Hans has fooled me.'

b. Hans hat mir keinen Bären aufgebunden.

Hans has me no bear up-tied

'Hans hasn't fooled me.'

(14) a. Hij heeft een scheve schaats gereden.

Dutch

He has a diagonal skate riden

'He made a mistake.'

b. Hij heeft geen scheve schaats gereden.

Hehas no diagonal skate riden

'He didn't make any mistake.'

(15) a. Mary has got a bone to pick with you.

'Mary has something to fight about with you.'

b. Mary has got no bone to pick with you.

'Mary doesn't have anything to fight about with you.'

Occurrences of NIs in idioms themselves are problematic if NIs are taken to be plain negative quantifiers. But what is important for the present discussion is the fact that NIs in idioms also invoke split readings when they are embedded under modal verbs. Thus also within idioms the negative component of NIs may outscope the operator that has scope over its indefinite part.

(16) Mir kannst du keinen Bären aufbinden.

German

Me can you no bear up-tie

'You can't fool me.'

(17) Hij mag geen scheve schaats meer rijden.

Dutch

He may no diagonal skate more ride

'He is not allowed to make anymore mistakes.'

(18) Mary can't have a bone to pick with you.

'It is not possible that Mary has something to fight about with you.'

\subsection{Concluding remarks}

The data presented above indicate that whenever a NI can take wide or narrow scope with respect to some particular operator, a third reading is available where the negation takes wide scope and the indefinite takes low scope and such split-scope readings are also available if, e.g., the narrow- or wide-scope reading is ruled out on independent grounds (as is the case with, for instance, object intensional verbs selecting NIs). These data are problematic for the assumption that NIs are negative quantifiers, since without adopting additional machinery a treatment of NIs as negative quantifiers cannot account for this third type of reading. 
In this paper I offer an alternative explanation of NIs, arguing that they constitute a piece of syntactic structure consisting of both a negative operator and an indefinite, that is morphophonolgically realized as a single morphological word. However, De Swart (2000) has shown that scope-splitting is not restricted to NIs but generally applies to monotone decreasing DPs (see (19) and (20)). This would cast doubt on any analysis that aims at explaining only split-scope effects occurring with NIs.

(19) Ze hoevenweinig verpleegkundigen te ontslaan.

Dutch

They need few nurses to fire

a. 'They are required to fire few nurses.'

$\neg>$ need $>\exists$

b. 'There are few nurses who they need to fire.'

c. *'They need to fire few nurses.'

$\neg>\exists>$ need

need $>\neg>\exists^{3}$

(20) You are required to read less than five books.

a. 'You are not required to read as many as five books.'

b. 'There are less than five books you are required to read.'

c. It is required that the number of books you read is less than five.'

Data like (19) and (20) at first sight call for a unified analysis of split-scope readings, but as has also been concluded by Penka (2007) closer inspection reveals that these constructions are to be analysed differently. Following Hackl (2000) and Heim (2006) monotone decreasing expressions, such as few or little, or comparatives, invoke split-scope readings due to the fact that these expressions are not plain generalized quantifiers but rather that they underlyingly consist of two quantifiers: one quantifier over individuals and one quantifier over degrees. Split-scope readings then follow automatically, since the degree quantifier can move to a position either scoping under or over the modal. This latter type of movement of the degree operator to a position higher than the modal then yields the split-scope reading (see Penka 2007 for a more detailed discussion of these facts).

Crucial, however, is that this mechanism that derives split-scope readings generated by monotone decreasing expressions, such as few or little or comparatives, does not naturally extend to split-scope readings of NIs as these do not exhibit two underlying quantifiers: NIs lack degree operators. Therefore split-scope readings involving NIs are still in need of explanation.

\section{Analysis}

The fact that the negative and the indefinite part of an NI in the languages discussed above may take scope from different positions is in need of explanation. In this section I formulate a proposal that accounts for this. In short, I propose that in these languages NIs constitute pieces of syntactic structure consisting of an abstract negative operator and a non-negative indefinite. Hence, the relation between the indefinite and this negative operator, $\mathrm{Op}_{\neg}$, is syntactically fixed and further merged in the derivation.

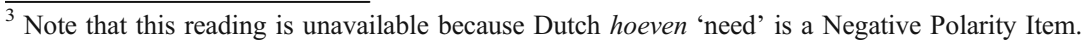


In subsection 3.1 I elaborate this proposal in more detail and in the subsequent subsections I demonstrate how the different possible readings can be derived for the NIs in the environments discussed in section 2: modal verbs (3.2), intensional verbs (3.3), and idiomatic expressions (3.4). Subsection 3.5 contains some concluding remarks.

\subsection{NIs as pieces of syntactic structure}

It is often assumed that NIs lack internal syntactic structure and that an NI is an atomic lexical item. In other words, the semantics of an NI is that of a negative quantifier and its semantic force is induced from one point in the syntactic structure. A simplified illustration is given in (21).

(21) No car is red

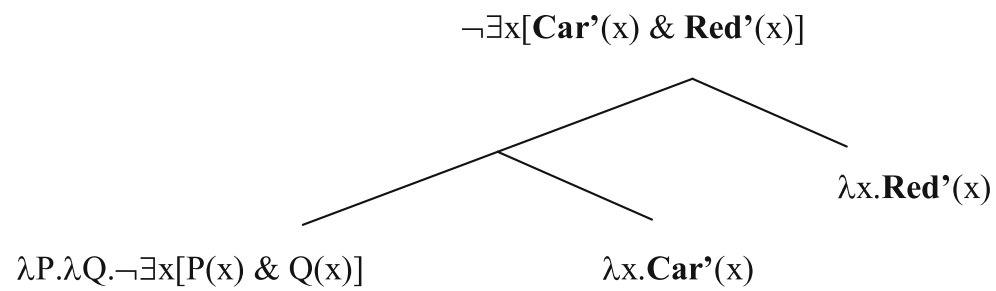

However, the structure in (21) is not the only way to generate the meaning of a construction containing an NI. Although from a morphosyntactic perspective (21) consists of three lexical elements (not taking the copula into account), semantically it exhibits at least four distinct objects: the predicates car and red, the indefinite, and the negation. From this semantic point of view it is far from unnatural to assume that all these objects can express their semantic force from a different point in the syntactic structure, as shown in (22). Since (22) yields exactly the same reading as (21), it follows that NIs do not have to be negative quantifiers: they can also be semantically non-negative, as long as there is some grammatical mechanism that forces a negative operator to enter the derivation along with the indefinite and that has to end up in an appropriate position.

(22) No car is red

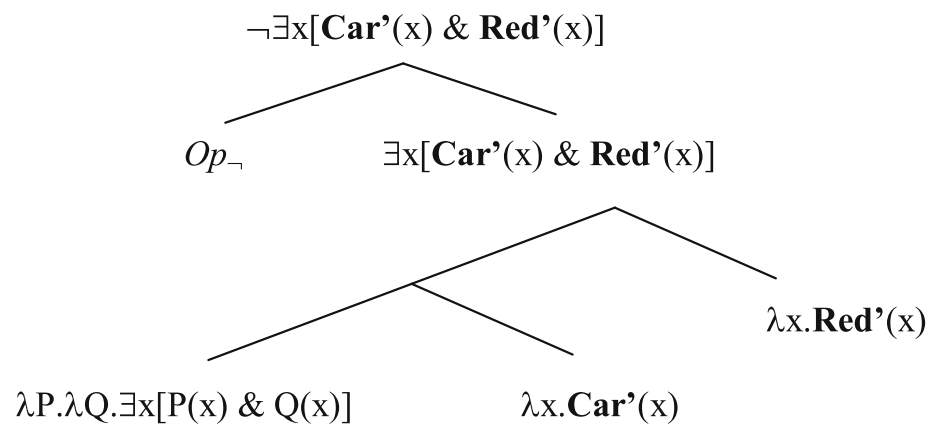


The main difference between (21) and (22) is that the indefinite and the negative operator occupy different positions in the structure. Consequently, the structure in (22), contrary to the structure in (21), does not prevent other material from intervening between the position of the negative operator to the indefinite. Once intervening material between the negation and the indefinite is allowed, the existence of split-scope readings follows as an immediate result. The question as to how the structure in (22) is derived is what everything boils down to and is therefore the topic of this section.

The fact that it is possible that the two parts of the NI form one unit at PF while simultaneously occupying two different structural positions at the level of LF introduces two questions. First, how does it follow from the structure in (22) that the two different nodes, the negation and the indefinite, are realized as one phonological object? Second, what is the relation between the negation and the indefinite such that on the one hand they are linked together (an NI is always a combination of one negation with one indefinite) but on the other hand they may appear in different LF positions in the structure?

In order to address these questions, I propose that an NI is the phonological realisation of a piece of syntactic structure. Hence, rather than merging with an atomic object, the derivation is expanded with another syntactic structure, which is spelled out as kein, geen or no for German, Dutch, and English respectively (a standard case of morphological fusion resulting in suppletive forms) in much the same manner as has been proposed for pronouns (Weerman and Evers-Vermeul 2002; Neeleman and Szendröi 2007) and for wh-terms (Barbiers et al. 2009). Now, the two problems immediately vanish: first, the fact that the complex structure corresponds to one phonological object follows straightforwardly; second, the fact that the relation between the negative operator and the indefinite is 1:1 follows as well: no object other than a syntactic structure consisting of those two nodes could be spelled out as kein/geen/no.

Given these considerations I argue that NIs in languages such as Dutch, German, and English are the results of a spell-out rule that realizes a syntactic structure consisting of a negative and an indefinite sister. An example of such a spell-out rule is given in (23) for German kein 'no'.

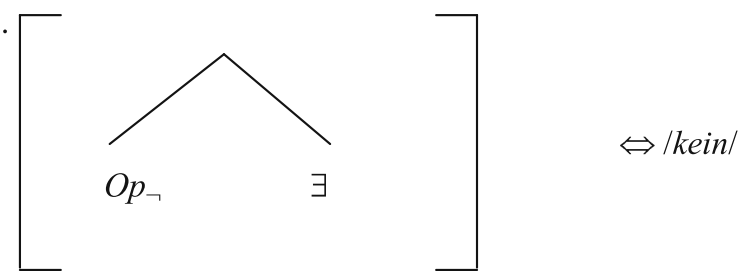

The figure in (23) shows that what is spelled out as kein is a syntactically and semantically complex piece of structure that contains both a negation and an indefinite component.

But it does not follow yet, how a spell-out rule such as (23) could allow for material intervening between the negation and the indefinite while still being spelled-out as one morphological word. 
However, since NIs under this proposal are not syntactically atomic they are not subject to the principle of lexical integrity that states that the internal structure of words is not accessible to syntax (Di Sciullo and Williams 1987; Ackema and Neeleman 2004). NIs are not created within the lexicon process (as a result of some morphological process), but they are the result of a syntactic process in accordance with some PF rule. Therefore NIs differ from morphologically negative words (being the output of the morphological component) such as unwise or non-smoker that will never give rise to split-scope effects. The NI thus forms a syntactic constituent that can be subject to syntactic operations such as Move. As I will illustrate in detail in the next subsection, this means that the entire NI, being quantificational in nature, can undergo QR (raising across another scope-taking element), followed by partial reconstruction of the indefinite part of the NI at the level of LF. As a result, then, at $\mathrm{PF}$ the entire copy is spelled out, whereas at LF the negation and the indefinite structure allow intervening, scope-taking material.

The syntactically complex status of NIs now enables us to derive a structure like the one in (22) and thus to derive split-scope readings. In the next subsection I demonstrate how the different readings of sentences consisting of a modal verb and an NI follow. In the section thereafter I show in a similar fashion how the different readings come about in sentences with an object intensional verb and in idiomatic expressions.

\subsection{Deriving the split-scope readings: modal verbs}

Let us reconsider data like (3) (presented here as subordinates, to avoid V2 effects). The LFs of the three readings are given in $(24 a-c)$, with the first one being the splitscope reading, the most salient one.

\section{...dass du keine Krawatte anziehen musst \\ ...that you no tie wear must}
a. '... that it is not obligatory that you wear a tie'
$\left[O p_{\neg}[\right.$ IP you [I must [vP a tie [v wear $\left.\left.\left.\left.]\right]\right]\right]\right]$
b. '... that there is no tie that you must wear'$$
\neg>\text { must }>\exists
$$
$\left[O p_{\neg}[\right.$ a tie [IP you [I must [VP wear]]]]]
c. '... that it is obligatory that you don't wear a tie' must $>\neg>\exists$ you [I must [vP $O p_{\neg}$ a tie [v wear]]]]

Let us first consider the base-generated structure, where the NI keine Krawatte ('no tie') is merged with the verb, which in turn merges with the modal verb musst 'must', under the standard assumption that modal verbs are base-generated in $\mathrm{I}^{\circ} .4$ Finally the subject merges and IP is created. ${ }^{5}$

\footnotetext{
${ }^{4}$ Note, though, that nothing crucial hinges on this assumption. If modals are base-generated in $\mathrm{V}^{\circ}$ the proposal makes the same predictions.

${ }^{5}$ The exact position where the subject is base-generated (Spec, $v \mathrm{P}$ or Spec,IP) is irrelevant for the present discussion.
} 
(25) Base-generated structure of (24):

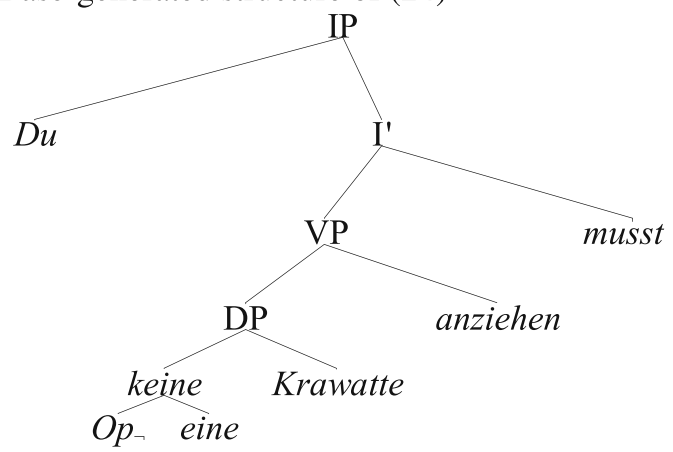

This base-generated structure already yields the narrow-scope reading (24c), where both the negation and the indefinite are in the scope of the modal verb. Now, the object is allowed to move under QR to a higher position to get wide scope. Adopting the copy and deletion theory of movement (Chomsky 1995), such a move creates a copy of the object raising under QR while the original element is subject to deletion. This is illustrated in (26).

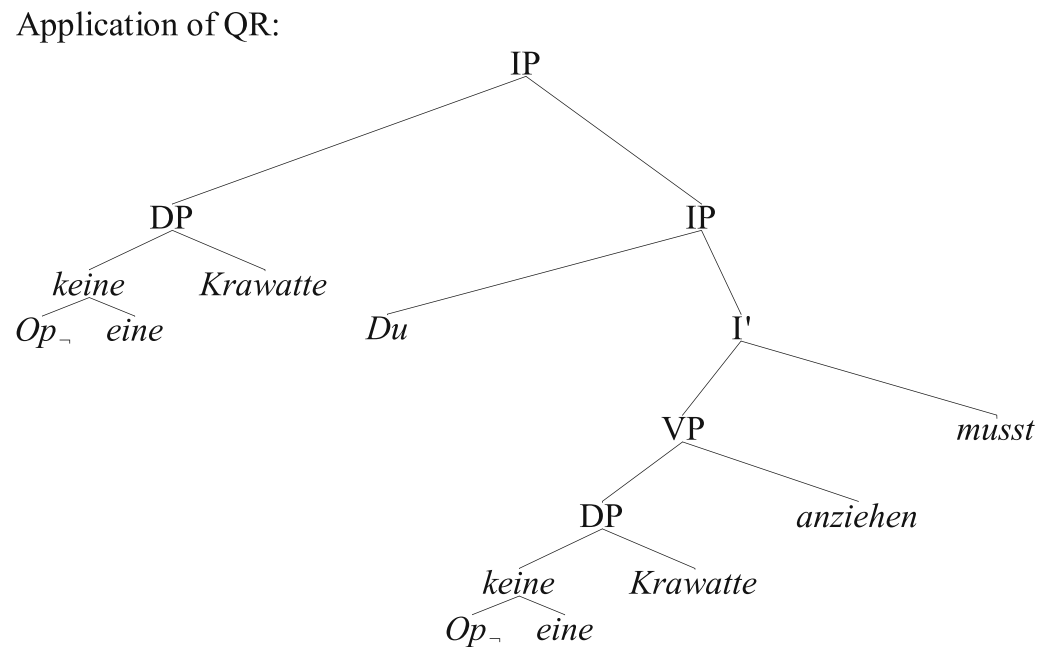

The structure in (26) contains two identical copies of the syntactic object [OP eine Krawatte], with the lower copy being interpreted phonologically, and the higher copy being interpreted semantically. The interpretation of the higher copy of this object yields the reading in which both the negation and the indefinite outscope the modal verb. The LF of this structure is given in (27).

(27) $\left[\mathrm{IP}\left[O p_{\neg} \text { eine Krawatte }\right]_{\mathrm{i}}\left[\mathrm{I}\left[\mathrm{vP}\right.\right.\right.$ du $\left[\Theta p_{\neg} \text {-eine Krawatte }\right]_{\mathrm{i}}$ anziehen $\left.]\right]$ musst $\left.]\right]$ 
However, as I have argued, the NI is not a syntactic atom, but rather constitutes a piece of syntactic structure. Given that $O p_{\neg}$ and the indefinite are sisters within that structure (and thus within each copy of that piece of structure), nothing requires that both be interpreted at LF in one and the same copy. Hence, it is possible as well that the semantic component interprets the negative operator within keine Krawatte in the higher copy and the indefinite in the lower copy. This yields the LF in (28), where the highest copy is partially reconstructed at LF (see Fox 1999; Fanselow and Cavar 2001, 2002 for more thorough discussion on the exact constraints on partial reconstruction; the view presented here for partial deletion basically mirrors Fanselow and Cavar's 2002 analysis of partial deletion at PF).

\section{[IP $\left[O p_{\neg} \text { eine Krawatte }\right]_{\mathrm{i}}\left[\mathrm{I}\left[\mathrm{vP} \mathrm{du}\left[\Theta p_{\neg} \text { eine Krawatte }\right]_{\mathrm{i}}\right.\right.$ anziehen] musst]]}

The reading that (28) yields is exactly the one where the negation outscopes the modal verb, whereas the modal verb in turn outscopes the indefinite: the split-scope reading. The assumption that NIs are syntactically complex lexical items, in accordance with the copy theory of movement, correctly predicts that a sentence like (24) gives rise to (at least) three readings, including the split-scope reading.

A potential problem for this analysis is that it seems to overgeneralise. In principle nothing would prevent the semantic component from interpreting the indefinite in the higher copy and the negative operator in the lower one, yielding a reading that is not possible for NIs. This reading cannot be obtained, however, on independent grounds. This is due to the fact that negation never reconstructs at the level of LF (cf. Horn 1989; Zanuttini 1997; Penka and von Stechow 2001; Zeijlstra 2004), a principle that is in line with the more general ban on adverbial reconstruction at $\mathrm{LF}^{6}{ }^{6}$

Thus, movement of the entire NI followed by partial reconstruction of the negative operator is blocked, as this violates the ban LF reconstruction of negation. In (29), the negative operator receives too low an interpretation. This implies that the negation may not be interpreted below if the indefinite is interpreted in the higher copy. Thus, the interpretation in which the indefinite outscopes the negation should be ruled out (30).

(29) $*\left[{ }_{\text {IP }}\left[O p_{\neg} \text { eine Krawatte }\right]_{\mathrm{i}}\left[\mathrm{I}\left[\mathrm{vP}\right.\right.\right.$ du $\left[O p_{\neg} \text { eine Krawatte }\right]_{\mathrm{i}}$ anziehen $]$ musst $\left.]\right]$

However, the question remains open as to why the reverse reading could not take place as a result of movement of the indefinite part out of the NI if the NI does not raise to the highest position itself, as is sketched in (30).

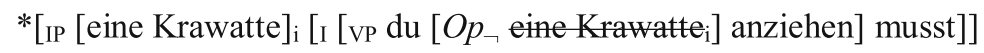

This structure in (30), however, can never be derived either. Note that under this proposal the internal structure of an NI such as keine Krawatte consists of merger of keine (in itself a merger of the negation with the indefinite) with the NP Krawatte:

$$
\left[\left[O p_{\neg} \text { eine }\right][\text { Krawatte }]\right]
$$

The only syntactic constituents containing the indefinite in a construction such as (30) that could undergo movement are thus either the entire structure in (31), which either gives

\footnotetext{
${ }^{6}$ See Gajewski (2007) for a series of examples that show that Neg-raising is different from LFreconstruction.
} 
rise to wide-scope or split-scope readings, or Krawatte by itself. The latter type of movement cannot give rise to a semantic effect, as the NP needs to remain in the scope of the indefinite in order to avoid semantic anomalies. Note however that some languages, e. g., German, are sometimes analyzed as allowing movement of the NP outside the NI, but if such raising is allowed, the interpretation of the NP remains in situ?

Bücher hat er keine geschrieben.
Books has he no written
'He hasn't written any books.'

German

It should be noted that (30) is also ruled out as a result of a more general constraint on movement that indefinites in principle are not allowed to raise across negation (cf. Beck 1996), a general constraint on movement, based on intervention effects, that applies to any theory of movement including the copy theory of movement in which the proposal is implemented. Such a constraint is independently motivated by examples such as the ones in (30) to prevent overgeneralization that may arise as a consequence of QR. NIs are not allowed to move across existential quantifiers and neither do these constructions give rise to split-scope readings:

$$
\begin{aligned}
& \text {... dat er iemand geen boek leest } \\
& \ldots \text { that there n-body no book reads } \\
& \text { '... that somebody reads no book' } \\
& \text { *.... that there is no book that somebody reads' } \\
& \text { *.... that there isn't anybody reading a book' }
\end{aligned}
$$

\section{Dutch}

$$
\begin{aligned}
& \exists_{\text {person }}>\neg>\exists_{\text {book }} \\
& \neg>\exists_{\text {book }}>\exists_{\text {person }} \\
& \neg>\exists_{\text {person }}>\exists_{\text {book }}
\end{aligned}
$$

Adopting a $\mathrm{QR}$ analysis would in principle allow for a reading where the entire NI could outscope the existential quantifier iemand ('nobody') as well as a splitscope reading. However, if such an instance of QR is banned on independent grounds, the analysis proposed here does not overgeneralise in this respect either.

However, the ban on movement across negation may be overcome in cases where the indefinite is heavy enough. Take for instance (34), which may actually receive a reading where there is a particular book that she didn't read.

(34) She didn't read a book (that was on the table).

Still, such readings are never available when the indefinite and the negation are both part of an NI:

(35) She read no book (that was on the table).

Hence, restrictions on QR, such as Beck's (1996) generalization, are not sufficient to rule out movement of the type indicated in (30). However, given the internal syntactic structure of the NI, such readings are ruled out anyway. Thus, there is no

\footnotetext{
${ }^{7}$ See Fanselow and Cavar (2002) for a discussion of these facts and how they are related to other partial deletion phenomena. Note that by no means do I want to suggest that cases such as (32) involve raising of Bücher ('books'). I only intend to show that if these constructions are analyzed as such, they do not form any counterexamples to what is claimed above.
} 
way in which the fourth reading can be derived and thus this or other potential problems of overgeneralization do not arise. ${ }^{8}$

\subsection{Deriving the split-scope readings: object intensional verbs}

The analysis also applies to split-scope readings in the case of object intensional verbs, such as German schulden 'to owe.' The only difference between these cases, illustrated in (36), and the cases with modal verbs is that the narrow-scope reading is not available either.

...dass Perikles Sokrates keinPferd schuldet

...that Perikles Sokrates no horse owes

a. '... that Perikles is not obliged to give Socrates a horse' $\neg>$ owe $>\exists$ $[O p \neg[$ IP Perikles [vP Socrates [vP a horse [v owes]]]]]

b. '... that there is no horse that P. is obliged to give to $S$ ' $\neg>\exists>$ owe [OP $p_{\neg}$ a horse [IP Perikles [vp Socrates [v owes]]]]

c. $\quad *$ *... that P. is obliged not to give Socrates a horse' owe $>\neg>\exists$ [IP Perikles [vP Socrates [vP $O p_{\neg}$ a horse [v owes]]]]

In a similar fashion to (26) the object moves to a Spec, IP position, and the structure in (37) is derived.

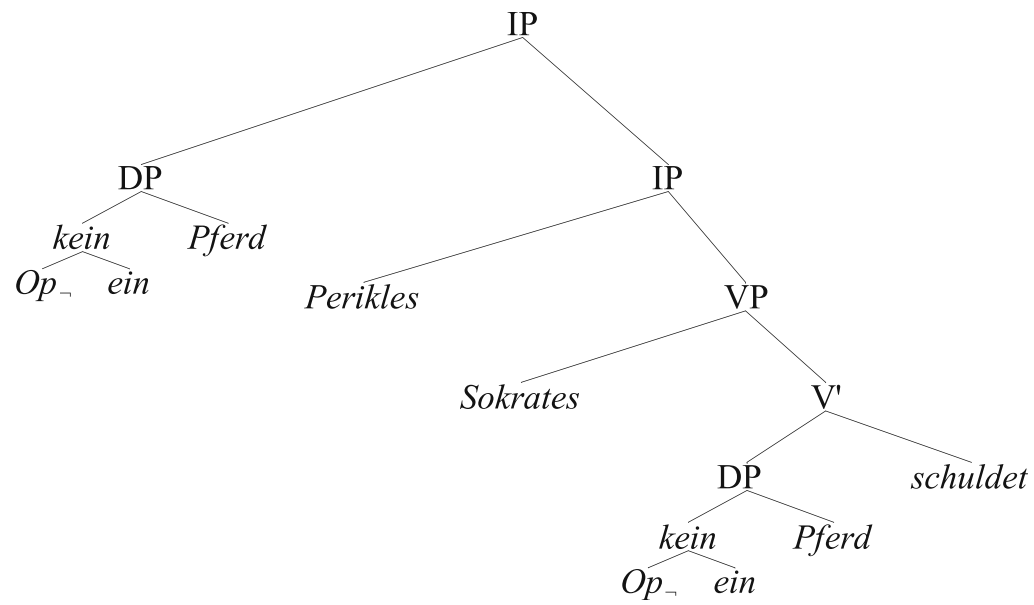

\footnotetext{
${ }^{8} \mathrm{~A}$ third possibility would be to assume, along the lines of Fanselow and Cavar (2002), that scopal relations within the copy be preserved. I.e., if in the base copy negation scopes over the indefinite, any copy + deletion process may not yield reverse scopal relations. Fanselow and Cavar (2002) propose a similar constraint (Parallel Movement Constraint after Müller 2007), not in terms of scopal relations, but in terms of c-command. However, since the negative operator and the indefinite are sisters, this particular proposal cannot be applied to rule out (29)-(30). Moreover, they present this principle as an OT constraint, which is therefore violable, whereas no cases of reverse split-scope readings of NIs have been attested. Future study should reveal whether this particular constraint could be extended to a more general principle in terms of conservation of scope relations within copies, though.
} 
Now the entire copy can be interpreted in the higher position, which yields the wide-scope reading (38).

$$
\left[O p_{\neg} \text { a horse [IP Per [vP Socrates [vP } O p_{\neg}\right. \text { a horse [v owes]]]]] }
$$

But, similar to the case of modal verbs, the negation may be interpreted high and the indefinite below. This yields the split-scope reading (39).

$$
\left[\Theta p_{\neg} \text { a horse [IP Per [vP Socrates [vP } O p_{\neg}\right. \text { a horse [v ]]]]] }
$$

The reading where the negation is interpreted low and the indefinite is interpreted high is ruled out due to the movement constraints discussed in the previous subsection.

The question remains open as to why the narrow-scope reading is not possible where both the negation and the indefinite are interpreted below. Zimmermann (1993) argues that object intensional verbs take properties but not quantifiers as their arguments (an analysis that is at odds with the analysis presented here), as can been seen from the fact that determiners that are invariably interpreted as quantifiers, such as every, cannot have a narrow-scope reading, as illustrated in (40).

(40) Hans seeks every unicorn.

(wide scope only)

It is unclear, however, whether this constraint results from the semantics of transitive intensional verbs, or from the pragmatics that make such utterances salient. Several examples containing NIs have been reported to be possible with a narrowscope reading like (41).

(41) For once, I need no children in the house. ${ }^{9}$

Hence, Zimmermann's account is probably too restrictive for these cases, and it seems that pragmatic constraints are involved (as well). Therefore I assume that the non-wellformedness of (42) follows from the pragmatics that goes with transitive intensional verbs, and that (42) is not syntactically ill-formed but is pragmatically and/or semantically infelicitous.

$$
{ }^{\#}\left[O p_{\neg} \text { a horse [IP Per [vP Socrates [vP } O p_{\neg}\right. \text { a horse [v owes]]]]] }
$$

The exact nature of this ban, however, is beyond the scope of this paper. Crucial for now is that the QR-based analysis predicts that NIs selected by object-intensional verbs give rise to split-scope readings, a prediction that is borne out.

\subsection{Deriving the split-scope readings: idiomatic expressions}

Finally, the analysis I presented above also accounts for the split-scope readings of sentences that combine an idiomatic expression with a modal verb. Let us (again) look at the German example in (43).

$$
\begin{aligned}
& \text {.. dass du mir keinen Bären aufbinden kannst } \\
& \text {.. that you me no bear up-tie can } \\
& \text { Literal: 'that it is not possible that you tie me up a bear' } \\
& \text { Idiomatic: 'that you can't fool me' }
\end{aligned}
$$

\footnotetext{
$\overline{9}$ The example is attributed to Von Fintel (exact reference unknown).
} 
Note that the exact idiomatic expression does not require the NI. The true idiomatic expression is rather einen Bären aufbinden (a bear up-tie 'to fool'). ${ }^{10}$ This is shown in (44) below:

(44) Du willst mir einen Bären aufbinden.

German

You want me a bear up-tie

'You want to fool me.'

In (43) again, the entire idiomatic expression (including the negation) is first merged within VP and later on the NI moves out of VP under QR to an IP-adjunct position.

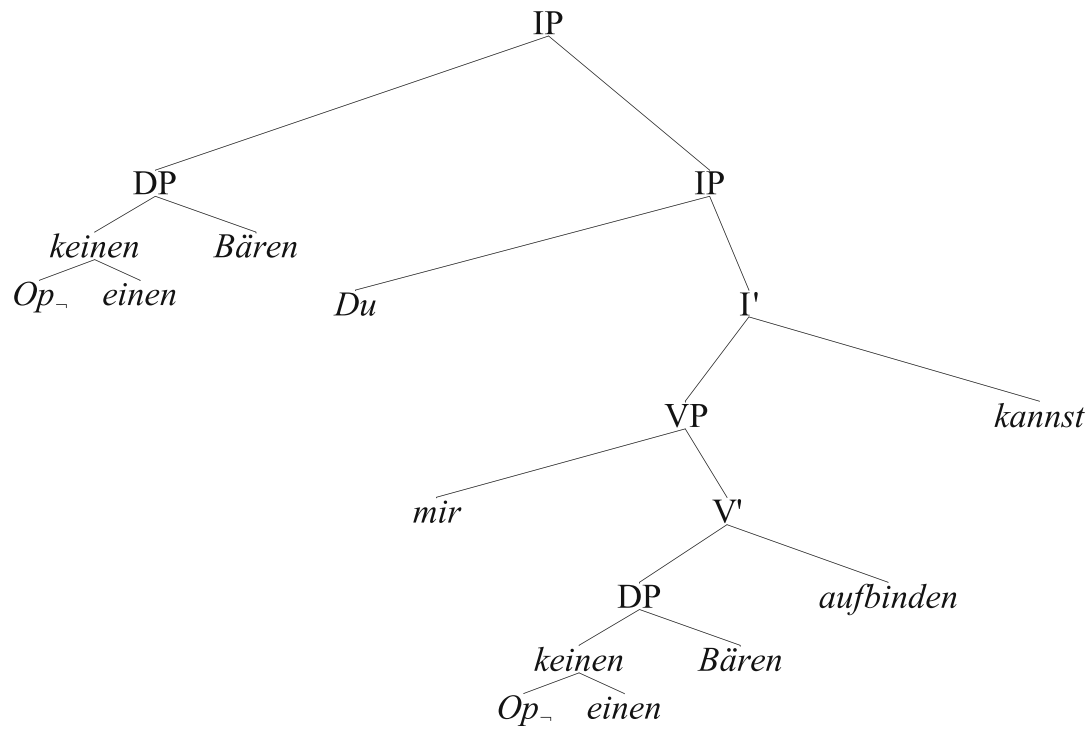

Now the lower negation and the higher indefinite may delete, under the copy and deletion theory of movement, yielding the structure (46) which correctly expresses the intended truth conditions.

$\left[O p_{\neg}\right.$ a bear $\left[\right.$ IP you $\left[\mathrm{I}\right.$ can $\left[\mathrm{vP}\right.$ me $\left[\mathrm{vP} \theta p_{\neg}\right.$ a bear $[\mathrm{v}$ tie up]]]]]]

${ }^{10}$ In some cases kein cannot be directly interchanged by ein. This is for instance the case in (i):

(i) Damit kommst du auf \{keinen/*einen $\}$ grünen Zweig. German

With.that come you at no/ a green twig

'You won't be successful with that.'

This is however not due to the fact that the negation is part of the idiom, but that the idiom is a negative polarity item. As shown below, the idiom containing a non-negative indefinite is well-formed when it is combined with, for example, a negative subject.

(ii) Niemand ist aufeinen grünen Zweig gekommen.

German

Nobody is at a green twig come

'Nobody has been successful.' 
Of course, the other possible readings are still available, either with a literal or idiomatic reading, as is shown in (47) for the narrow-scope reading (literal and idiomatic) and (48) for the wide-scope reading (only literal).

[IP you [I can [vP me [vP $O p_{\neg}$ a bear [v tie up]]]]]

$$
\left[O p_{\neg} \text { a bear [IP you [I can [vP me [vP } O p_{\neg}\right. \text { a bear [v tie up]]]]]] }
$$

A crucial step in this line of argumentation is that the idiom (einen Bären aufbinden) needs to be interpreted as a unit. That is, the idiomatic reading is only available if the indefinite is interpreted within the VP. Therefore (48), which represents the wide-scope reading of (43), only receives the non-literal reading. It should be noted that under this analysis the syntactic process of QR precedes the non-literal interpretation of the idiomatic expression, even when the non-literal reading itself does not involve quantification.

\subsection{Concluding remarks}

The analysis presented above explains how split-scope readings arise and how they are constrained. It does so by assuming that NIs such as German kein constitute syntactic structures (as is thought to be the case with pronouns and wh-terms). As a result of $\mathrm{QR}$ and the syntactic principle that demands that copies need to be deleted, split-scope readings are expected to arise as well. Note the entire analysis does not allude to any principle that has not been independently motivated.

Apart from the emergence of split-scope readings, the proposal solves another problem concerning the interaction between NIs and ellipsis. German and Dutch NIs that are deleted under ellipsis may sometimes seem to have lost their negation, as illustrated in (49) and (50) for German and for Dutch.

... dasser im Garten keinen Mensch antraf und im Haus auch nicht

... thathe in.thegarden no person met and in.thehouse also neg

'... that he didn't encounter anybody in the garden nor in the house'

(50) ... dat hij geen mens in de tuin aantrof en ook niet in het huis

... that he no person in the gardensaw and alsoneg in the house

'... that he didn't encounter anybody in the garden nor in the house'

Given that deletion may only take place under semantic identity (cf. Merchant 2001) it is strange that the deleted VP in the second clause does not contain a negation. After all, the expected underlying representation of (49) would be (51), which would be expected to contain a negation of its own, as shown below (where double strikethrough indicates deletion under ellipsis):

\section{... dass er im Garten [vp keinen Mensch antraf] und im Haus auch nicht [keinen Mensch antraf]}

But following the analysis pursued in this section, it is in fact expected that the negation does not have to be part of the deleted VP: the fact that QR may apply followed by partial reconstruction makes it possible that only the indefinite is 
interpreted in situ in the first conjunct and not the negative operator. Consequently the deleted VP does not have to carry a semantic negation either ${ }^{11}$ :

(52)... dass er im Garten [ $O p_{\neg}$ einen Menseh] [vP [ $O p_{\neg}$ einen Mensch] antraf] und im Haus auch nicht [vP

Note that so far this only partially answers the question why the deleted VPs in (49) and (50) must be interpreted non-negatively: the account only makes it possible, not obligatory. The obligatory non-negative interpretation however is required due to the contribution of auch nicht in German and ook niet in Dutch. German auch nicht and Dutch ook niet can only be felicitously included in the second conjunct of a sentence if the first conjunct is negative and it is auch nicht/ook niet (not anything else) that renders the second conjunct negative, as shown below:

a. Er hat (*nicht) gegessen und auch nicht getrunken. German He has neg eaten and also neg drunk

'He didn't eat, and neither did he drink.'

*'He didn't eat, and neither did he not drink.'

b. Hij heeft (*niet) gegeten en ook niet gedronken. Dutch He has neg eaten and also neg drunk

'He didn't eat, and neither did he drink.'

*'He didn't eat, and neither did he not drink.'

The data in (53) show that the negation may not be part of the deleted part of the second conjunct as a result of the semantic/pragmatic behaviour of auch nicht/ook niet. Similarly, the deleted VPs in (49) and (50) may not contain a negation either, which can only be the case if the VPs in the first conjuncts do not do so either.

Note that this analysis predicts that in those cases, the first conjunct may only receive a split-scope reading, as it is only under the split-scope reading that the VPs of both the first and the second conjunct contain only the indefinites, a prediction that is indeed borne out:

(54) Du musst am Vormittag keine Krawatte anziehen You must in.theevening no tie wear und am Nachmittag auch nicht.

German and in.the morning also neg

a. 'It is not required that you wear a tie.'

$\neg>$ must $>\exists$

b. *'There is no tie that you are required to wear.'

$\neg>\exists>$ must

c. '*It is required that you don't wear a tie.'

must $>\neg>\exists$

\footnotetext{
${ }^{11}$ Note that the deleted constituent is simply a positive indefinite followed by an NP (in casu [einen Mensch]), which does not contain any deleted negation in the first place.
} 
(55) $\mathrm{Ze}$ mogen in het ziekenhuis geen verpleegkundige ontslaan They may in the hospital no nurse fire en in de kliniek ook niet.

Dutch and in the clinic also neg
a. 'They are not allowed to fire any nurse.'
$\neg>$ may $>\exists$
b. *'There is no nurse who they are allowed to fire.'
$\neg>\exists>$ may
c. *'They are allowed not to fire a nurse.'
may $>\neg>\exists$

\section{Comparison to previous accounts}

The facts presented above strongly indicate that NIs should be considered different from negative quantifiers and the presented analysis correctly predicts how and when split-scope readings may arise. In this section, I evaluate other analyses that have attempted to cope with the problems introduced in section 2. First, I discuss a previous analysis by Jacobs (1980) and Rullmann (1995), who posit that NIs result from amalgamation or incorporation processes. After that I evaluate two accounts, by Geurts (1996) and by De Swart (2000), which have maintained that NIs are negative quantifiers despite the facts that seem to argue against this analysis. Finally, I discuss recent work by Penka (2007) who takes the opposite view and argues that NIs in Dutch and German are semantically non-negative and are equipped with a formal licensing condition that requires them to be bound by an abstract negative operator. Penka's main claim is that Negative Concord and split-scope readings are two sides of the same coin and she argues that the two phenomena ought to be analysed analogously.

In this section I show that despite surface similarities with the presented analysis these accounts all face problems, which do not arise under the presented analysis.

\subsection{Jacobs (1980)/Rullmann (1995): amalgamation and incorporation}

One of the first analyses of this phenomenon was Jacobs' (1980) (very close in essence to the analysis I propose), which states that in German the negative marker nicht amalgamates with an indefinite, e.g., jemand ('somebody') or etwas 'something'. That is to say that an adjacent negative marker nicht and indefinite ein fuse into the single word kein.

Penka (2007) argues that such an amalgamation process is problematic in grammatical frameworks that assume different levels for semantic and phonological representations. Since such an amalgamation rule cannot take place at the level of LF (otherwise the split-scope reading could never be derived), it must be purely phonological and take place at PF. But this requires a phonological rule that, e.g., renders nicht and etwas into nichts. Such phonological rules are not known in any other phonological processes.

One could assume (as I do as well), though, that amalgamation does not apply to the negative marker or indefinites such as jemand or etwas but that it applies to abstract material: an abstract negative operator and/or an abstract determiner. For Penka, this only makes things worse: abstract material, i.e., material that lacks phonological content in the first place, is invisible at PF; hence no amalgamation rule can apply. 
A similar approach is the proposal put forward by Rullmann (1995) based on Klima's (1964) rules of incorporation. If superficially the negation and the indefinite are adjacent, the negation incorporates in the indefinite yielding an NI. For Dutch niet and geen this would be:

$$
\text { niet } \mathrm{D}_{\text {indef }} \Rightarrow \text { geen }
$$

But Penka argues that the same problems evident for the amalgamation process show up again. Since LF incorporation does not take place when lexical material is allowed to intervene between the negation and the indefinite, incorporation must take place again at PF. But incorporation at PF is allowed not only for overt indefinites (such as Dutch een), but also for the zero determiner, as shown in (57)-(58).

a. Ze mogen een verpleegkundige ontslaan.

Dutch

They may a nurse fire

'They are allowed to fire a nurse.'

b. Ze mogen geen verpleegkundige ontslaan.

They may no nurse fire

'They are not allowed to fire any nurse.'

a. Ze mogen verpleegkundigen ontslaan.

Dutch

They may nurses fire
'They are allowed to fire nurses.'

b. Ze mogen geen verpleegkundigen ontslaan.

They may no nurses fire

'They are not allowed to fire any nurses.'

Whereas in (57) negation seems to have incorporated into the indefinite article een, in (58) incorporation must have taken place in an abstract element. But, once again, such elements that lack phonological content are invisible at PF. Hence, for Penka, Rullmann's analysis faces the same problems as Jacobs (1980): in order to account for the split-scope readings that are derived at LF, NIs are suggested to be the result of an incorporation process, which may only take place at a moment in the derivation that does not affect interpretation.

All these criticisms are based on specific views on what kind of rules are allowed at the phonology-morphology-syntax interfaces. Under a purely lexicalist point of view (where every lexical item comes in with all its phonological features present), Penka's arguments seem to be correct. But over the past decade the works on Distributed Morphology (Halle \& Marantz 1993 and subsequent work) have provided frameworks whereby morpho-phonological realization takes place after spell-out, i.e., abstract syntactic structures are the input for morpho-phonological processes. Under such a view of the syntaxmorphology interface, Penka's arguments against amalgamation or incorporation lose their validity.

However, an analysis only in terms of post-syntactic morpho-phonological realisation is a necessary but not sufficient analysis of the facts. Both Jacobs' and Rullmann's proposals, rephrased in terms of post-syntactic spell-out, crucially rely on phonological string-adjacency of the negation and the indefinite; the gist of the 
analysis is that what appears as adjacency at surface structure does not have to be structurally adjacent at the level of LF:

[NEG [eine Krawatte anziehen [musst]]]

In (59) NEG and eine Krawatte may somehow be spelled out as keine Krawatte, even though the indefinite scopes under the modal, whereas the modal scopes above. However, such a mechanism would not directly apply if the language in question were $\mathrm{VO}$ instead of $\mathrm{OV}$, as then such a configuration would no longer be possible. However, as demonstrated in section 2, English, being an SVO language, allows split-scope readings as well, although the ( $v \mathrm{P}$-external) position where negation is interpreted at LF is never string-adjacent to the (postverbal) position where the indefinite appears at PF.

(60) You have to do no homework.

The final step that, thus, needs to be taken, is that kein/geen/no should not be considered as the phonological realisation of two string-adjacent elements at the level of PF, but as the realisation of a piece of syntactic structure that consists of a top node dominating two syntactic sisters: the negation and the indefinite. ${ }^{12}$ Then, it follows naturally that in a language like English (and mutatis mutandis also in Dutch/German) the negation and the indefinite are first merged together and then merged with the NP, constituting the negative DP no homework, which gets spelled out as such. After spell-out, under QR this entire DP raises to a higher position, after which partial reconstruction may take place to yield the split-scope reading.

So, the major difference between the analysis presented in this paper and Jacobs' and Rullmann's analyses is that in the former negation is always part of the NI (until the level of LF when partial deletion may apply), whereas in the latter NIs result from coincidental string-adjacency of the negation to the indefinite.

\subsection{Geurts (1996): quantification over abstract individuals}

Geurts (1996) tries to overcome the problems of taking NIs to be negative quantifiers by arguing that split readings of NIs arise when the article kein does not quantify over simple individuals as usual, but rather over kinds in the sense of Carlson (1977). He derives the split reading of (61) as sketched in (62).

(61) Ich suchekeine Putzfrau.

German

I seek no cleaning.lady

'I'm not looking for a cleaning lady.'

(62) a. [no cleaning lady $] \lambda x$. I seek $x$

b. $\neg \exists \mathrm{x} \in\{$ CLEANING LADY $\}$ : I seek $\mathrm{x}$

First, the negative quantifier keine Putzfrau moves across the verb at LF (62a). Geurts then assumes that kein in this configuration quantifies over the singleton set consisting

\footnotetext{
12 Thanks to Susi Wurmbrand (p.c.) for pointing this out to me.
} 
only of the kind term CLEANING LADY. This gives (62b), which asserts that the speaker is not a cleaning-lady seeker. This is equivalent to the reading in which the indefinite quantifier ranges over concrete individuals and the negation has wide scope: the splitscope reading.

But Geurts' proposal has a number of problems, both conceptually and empirically (see De Swart 2000 for a more thorough discussion of these problems). First, he cannot simply appeal to the notion of abstract individual or natural kind as used in Carlson (1977). To account for split readings in some cases very specific and strange kinds would have to be assumed. For instance, to get the paraphrased reading of (63), Geurts would have to appeal to the kind "student who attended Arnim's lecture yesterday”.

(63) Ich suchekeinen Student, der gestern in Arnims Vorlesung war. German I seek no student who yesterday in Arnim's lecture was

'I'm not looking for a student who attended Arnim's lecture yesterday.'

Another problem for this analysis is the fact that kein can combine with numerals while scope splitting is still possible. It remains unclear how Geurts' account could deal with a sentence such as (64) under the reading paraphrased, as two cars does not refer to a particular kind in terms of Carlson (1977).

(64) Wir müssen keine zwei Autos haben.

German

We must no two cars have

'We don't need to have two cars.'

Even more devastating is the fact that NIs can occur in idiomatic expressions and give rise to split-scope readings, as shown in (65)-(66). Occurrences of NIs in idioms themselves are a problem for the negative quantifier analysis. But what is important for the present discussion is the fact that NIs in idioms also yield split readings when they are embedded under modal verbs:

(65) Mir kannst du keinen Bären aufbinden.

German

Mecan you no bear up-tie

'You can't fool me.'

(66) Hij mag geen scheve schaats meer rijden.

Dutch

He may no diagonal skate more ride

'He is not allowed to make any more mistakes.'

In the cases of (65) and (66), the split reading cannot be derived by assuming quantification over abstract individuals, since this would only yield the literal interpretation. To get the idiomatic meaning of the expression (k)einen Bären aufbinden in (65) the indefinite must be interpreted together with the rest of the 
idiom in the scope of the modal while the negation still takes wide scope. The same holds for the Dutch example.

4.3 De Swart (2000): higher-order quantification

The account of De Swart (2000) is similar to that of Geurts (1996) insofar as both assume that some special kind of quantification is responsible for scope splitting of NIs, thus maintaining the quantificational status of NIs. But rather than assuming quantification over abstract individuals, which causes several of the above-mentioned problems, De Swart (2000) employs higher-order quantification. She argues that scope splitting occurs when kein quantifies over properties and proposes that there is an additional lexical entry for kein according to which kein is a negative quantifier over properties:

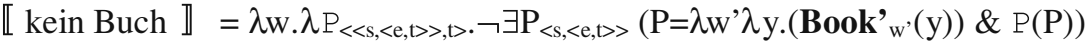

Using this translation for kein then derives the split-scope reading for the sentence in (68) as sketched in (69):

(68) Hanna sucht kein Buch.

German Hanna seeks no book

(69) no book (seek) (hanna)

$\neg \exists \mathrm{P}\left(\mathrm{P}=\lambda \mathrm{w}^{\prime} . \lambda \mathrm{y} .\left(\right.\right.$ Book'$\left._{\mathrm{w}^{\prime}}(\mathrm{y})\right)$ \& Seek'(h,P) $^{\prime}$

$=\neg$ Seek' $^{\prime}\left(\mathbf{h}, \lambda \mathrm{w}^{\prime} \cdot \lambda \mathrm{y} \cdot\left(\right.\right.$ Book' $\left._{\mathrm{w}},(\mathrm{y})\right)$

'Hanna is not a book seeker.'

='Hanna doesn't seek a book.'

But, as Penka (2007) has pointed out, there are reasons to believe that higher-order quantification is not what is responsible for scope splitting. First, such an analysis cannot derive intermediate scope readings of the indefinite for sentences with two scope-bearing elements besides negation and the indefinite, i.e., readings in which the negation takes widest scope and the indefinite takes scope in between the two operators. This is the case because the higher-order interpretation of kein invariably gives the indefinite narrowest scope. De Swart claims that this is actually a virtue of her analysis and argues that intermediate scope readings are not available for NIs, an argument she puts forward against Kratzer (1995). But this claim seems to be empirically too strong. For example, the sentence in (70) does indeed have the reading paraphrased, in which negation takes widest scope and the indefinite scopes in between kann 'can' and wollen 'want'. This is confirmed by the fact that the speaker can elaborate on (70) with "as she doesn't know one". If the indefinite necessarily had narrow scope with respect to 'want', this continuation would not be felicitous, because Julia might still have the idea that Norwegians make good husbands and want to marry some Norwegian or other even without knowing any Norwegian.

(70) Julia kann keinen Norweger heiraten wollen.

German

Julia can no Norwegian marry want

'It's not possible that there is a Norwegian that J. wants to marry.' $>>$ can $>\exists>$ want 
Moreover, the fact that NIs in idioms can have a split reading is also a problem for De Swart's account. The NI somehow has to isolate itself from the idiom to be able to apply to the remaining property. But if the NI is part of the idiom itself (e.g., in (65) and (66)) the idiom cannot be interpreted en bloc anymore, a crucial property for the interpretation of idioms. The prediction is thus made that split-scope readings of idiomatic expressions receive a literal reading, contrary to fact. Hence (65) and (66) are also problematic for this analysis.

Note that this problem does not appear under the analysis I have proposed, as the indefinite part of the idiom will be interpreted in the lower copy of the NI, whereas negation will be interpreted in the higher copy. The actual idiom that needs to be interpreted as a unit thus still contains the indefinite, but not necessarily the negation (see section 2.3 for the relevant data).

\subsection{Penka (2007): NIs are n-words}

A recent analysis that is the opposite of Geurt's and De Swart's analyses is Penka's (2007) that takes NIs to be semantically non-negative. Penka (2007), following Penka (2002) and Penka and von Stechow (2001), draws a parallel between splitscope readings of NIs and Negative Concord, the phenomenon where multiple morphosyntactically negative elements yield only one semantic negation, as illustrated for Italian and Czech below:

(71) a. Non telefona nessuno.

Italian

Neg calls $n$-body

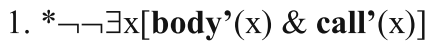

2. $\neg \exists x\left[\operatorname{body} y^{\prime}(x) \&\right.$ call' $\left.(x)\right]$

b. Nessuno dice niente.

$N$-body says n-thing

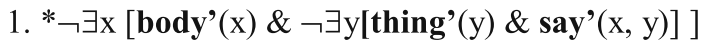

2. $\neg \exists x\left[\operatorname{body}^{\prime}(x) \& \exists y\left[\right.\right.$ thing' $(y) \&$ say'$\left.\left.^{\prime}(x, y)\right]\right]$

(72) a. Nevolá nikdo.

Neg.calls n-body

Czech

1. * $\neg \neg \exists x[$ body'(x) \& call'(x)]

2. $\neg \exists x\left[\operatorname{body} y^{\prime}(x) \&\right.$ call'(x)]

b. Nikdo nedá nikomu nic

$N$-body neg.gave n-body n-thing

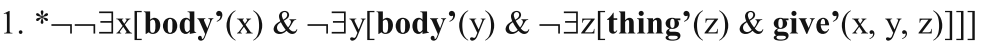

2. $\neg \exists x\left[\operatorname{body}^{\prime}(x) \& \exists y\left[\operatorname{body} y^{\prime}(y)\right.\right.$ thing'(z) \& $\exists[$ give'(x, y, z)]]]

Penka adopts Zeijlstra's (2004, 2008) analysis of Negative Concord, where nwords (in Negative Concord languages) are taken to be semantically non-negative, carrying an uninterpretable negative feature ([uNEG]) which needs to be checked against a negative operator, which may be phonologically abstract. The examples given in (71) and (72) would then receive the following syntactic and semantic 
representations (for more discussion of these and similar data, see Zeijlstra 2004, 2008 and Penka 2007):

a. $\left[\right.$ Non $_{[\mathrm{iNEG}]}$ telefona nessuno $\left.{ }_{[\mathrm{uNEG}]}\right]$ $\neg \exists \mathrm{x}\left[\operatorname{body} \mathbf{y}^{\prime}(\mathrm{x}) \&\right.$ call'(x)]

b. $\left[O p_{-[\mathrm{iNEG}]}\right.$ nessuno $_{[\mathrm{uNEG}]}$ dice niente $\left._{[\mathrm{uNEG}]}\right]$ $\neg \exists \mathrm{x} \exists \mathrm{y}\left[\operatorname{body}{ }^{\prime}(\mathrm{x}) \&\right.$ thing'(y) \& $\left.\operatorname{say}^{\prime}(\mathrm{x}, \mathrm{y})\right]$
a. $\left[O p_{-[\mathrm{iNEG}]}\right.$ nevolá ${ }_{[\mathrm{uNEG}]}$ nikdo $\left._{[\mathrm{uNEG}]}\right]$ $\neg \exists \mathrm{x}[$ body'(x) \& call'(x)]
b. $\left[O p \neg_{[\mathrm{iNEG}]}\right.$ nikdo $_{[\mathrm{uNEG}]}$ nedá $_{[\mathrm{uNEG}]}$ nikomu $_{[\mathrm{uNEG}]}$ nic $\left._{[\mathrm{uNEG}]}\right]$ $\neg \exists \mathrm{x} \exists \mathrm{y} \exists \mathrm{z}\left[\operatorname{body}{ }^{\prime}(\mathrm{x}) \&\right.$ body'$^{\prime}(\mathrm{y})$ thing'(z) \& give'(x, y, z)]

In short, the highest element carrying [uNEG] is always immediately dominated by a negative operator, be it overt (like Italian non) or covert $\left(O p_{\neg[\text { iNEG }]}\right)$.

Penka argues that in Dutch and German the same process is going on, the only difference being that multiple agreement with respect to negation is not allowed in these languages. Hence, every NI is a semantically non-negative indefinite carrying a [uNEG] feature and needs to have its feature checked against an abstract negative operator $O p_{-[\mathrm{iNEG}]}$. In case two NIs show up in the sentence each NI must licensed by a separate $O p_{-[\mathrm{iNEG}] \text {. }}$

Thus Penka derives split-scope readings by having the abstract negative operator outscope the intervening scope-taking operator, which in turn outscopes the indefinite DP, as illustrated in (75).

$\begin{array}{lll}\text {... dass Du keine Krawatte anziehen musst } & \text { German } \\ \ldots \text { that you no tie wear must } & \\ {\left[\text { dass Du }\left[O p_{\mathrm{NEG}[\mathrm{iNEG}]}\left[\left[\mathrm{keine}_{[\mathrm{uNEG}]} \text { Krawatte anziehen }\right] \text { musst }\right]\right]\right]} & \\ \text { 'It is not required that you wear a tie.' } & >\text { must }>\exists\end{array}$

However, at least two problems arise for this analysis. First it is not clear what determines the licensing conditions of the abstract negative operator. In Zeijlstra $(2004,2008)$ it is explicitly stated that the $O p \neg$ may only be introduced in a derivation immediately dominating the highest element carrying [uNEG]. Hence, under this condition the splitscope reading could not be derived, as no material may intervene between $O p \neg$ and the indefinite. Penka (2007) states that adjacency at surface structure is the proper licensing domain for NIs, otherwise the three readings in (76) could not have been derived.

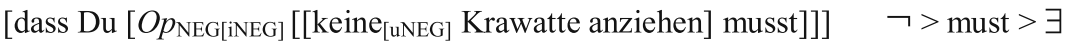

$$
\begin{aligned}
& \text { [dass Du [O } p_{\mathrm{NEG}[\mathrm{iNEG}}\left[\mathrm{keine}_{[\mathrm{uNEG}]} \text { Krawatte [anziehen musst]]]] } \neg>\exists>\right.\text { must } \\
& \text { [dass } \mathrm{Du}\left[\left[O p_{\mathrm{NEG}[\mathrm{iNEG}]}\left[\text { keine }_{[\mathrm{uNEG}]} \text { Krawatte anziehen] }\right] \text { musst }\right]\right] \text { must }>\neg>\exists
\end{aligned}
$$

However, linear adjacency is not a notion that applies at the level of surface structure, but at the level of PF. Surface structure is not about linearization: that is a process that takes place at PF. For the derivation it does not make any difference whether two elements precede or follow each other. At Spell-out the two structures in (77) are identical:

$$
\begin{aligned}
& {[\mathrm{A}[\mathrm{B} C]]} \\
& {[\mathrm{A}[\mathrm{C} \text { B]] }}
\end{aligned}
$$

Only at PF do the two structures diverge. So, Penka's approach is in some way the mirror version of Jacob's and Rullmann's analyses: whenever an NI appears at surface 
structure, apparently $O p\urcorner$ should be presumed to be left-adjacent to it. But this leads to the problems that these analyses face, which she relates to Jacob's and Rullmann's approaches, but which still persist in the purely lexicalist view she adopts. Moreover, it would no longer be possible to account for the split-scope readings in English VO constructions, as there the position left-adjacent to the NI is not a position where negation takes scope. ${ }^{13}$

Second, Penka (2007) takes every language to exhibit formal negative features and reduces the difference between Negative Concord and Double Negation languages (i.e., languages that always exhibit a 1:1 correspondence between morphosyntactic and semantic negation) to a single parameter, namely whether negative agreement may be subject to multiple agreement or not. Zeijlstra (2004, 2008), on the other hand, states that only real Negative Concord languages have a formal negative feature and that in Double Negation languages the negative feature does not have any formal status: it is a purely semantic feature. As the main argument for this, Zeijlstra demonstrates that the acquisition of formal negative features in a Double Negation language is impossible. Moreover, Zeijlstra argues that this analysis makes a strong empirical prediction, namely that if non-Negative Concord languages do not have a formal negative feature at their disposal, they cannot project such a feature either (following Giorgi and Pianesi 1997), as illustrated in (78).
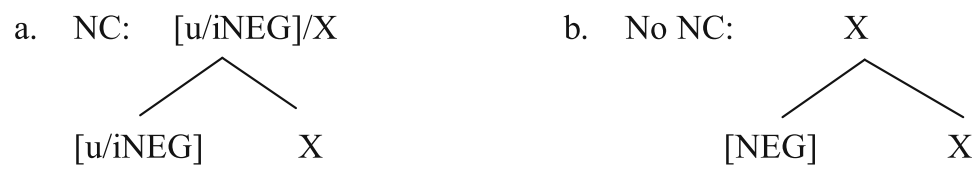

As a result negative heads $\left(\mathrm{X}^{\circ}\right)$ are predicted not to be available in non-Negative Concord languages. This prediction is borne out (on the basis of an extensive crosslinguistic and language-internal survey, cf. Zeijlstra (2004)): there is no language without Negative Concord that exhibits a negative marker that is a syntactic head. ${ }^{14}$ This prediction remains unexplained though under Penka's analysis where every language has a formal negative feature. Now, this is not a principled argument against Penka, as she may argue that this unidirectional relation is motivated by something else, but if two different analyses of split-scope have more or less the same explanatory power and one is compatible with the only explanation thus far for some other phenomenon, whereas the other is not, this speaks in favour of the first analysis, i.e., the lexical analysis.

\footnotetext{
${ }^{13}$ Note that the only option for repairing this would be to state that then $O p_{\neg}$ is presumed to be a syntactic sister of keine, and that [[OP $\neg$ keine $] \mathrm{NP}]$ undergoes $\mathrm{QR}$, followed by partial reconstruction, an option not taken into account by Penka. However, if QR plus partial reconstruction is taken to be the source of split-scope readings, nothing motivates any more the additional assumptions Penka has to make (such as the underlying syntactic negative agreement relation that is subject to some stipulated 'no multiple agree' parameter in these constructions), as the existence of split-scope readings already follows without them.

${ }^{14}$ See Zeijlstra $(2004,2008)$ for a treatment of languages that at first sight seem to violate this prediction (such as Standard British English).
} 
To conclude, Penka's analysis, which tries to unify Negative Concord and splitscope readings, faces problems that the QR-based analysis for split-scope does not suffer from. As it stands, despite surface similarities, split-scope effects and Negative Concord seem to differ much more in nature and Zeijlstra's theory of NC cannot be naturally extended to split-scope constructions without seriously modifying it to such an extent that it seriously loses its explanatory force with respect to Negative Concord.

\section{Conclusions}

In this paper I have argued that NIs in languages like Dutch, German, and English are not negative quantifiers (in the Montegovian sense), but pieces of syntactic structure that consist of a negative operator and an indefinite, which postsyntactically are spelled-out as a single morphological word. Split-scope effects are derived as a result of the copy theory of movement. I have proposed that in splitscope constructions after Quantifier Raising the negative operator is interpreted in a higher copy and the indefinite in a lower copy of the NI. Furthermore I have demonstrated that alternative analyses that take NIs in Dutch and German to be negative quantifiers, n-words, or the result of amalgamation or incorporation processes face problems that the analysis presented in this paper does not encounter.

Acknowledgements This work has resulted from various discussions with Doris Penka on split-scope phenomena to a joint presentation at CGSW 20 in Tilburg. Although we did not end up agreeing, I am much indebted and her valuable comments and ideas. This work has also benefited from many discussions with Arnim von Stechow and Sabine Iatridou and the participants of the More Advanced Syntax class taught at MIT in the spring of 2009. Finally, Susi Wurmbrand deserves all the credit for proposing important modifications to the analysis. All errors and unclarities, of course, are mine.

Open Access This article is distributed under the terms of the Creative Commons Attribution Noncommercial License which permits any noncommercial use, distribution, and reproduction in any medium, provided the original author(s) and source are credited.

\section{References}

Ackema, Peter, and Ad Neeleman. 2004. Beyond morphology; interface conditions on word formation. Studies in theoretical linguistics. Oxford: Oxford University Press.

Barbiers, Sjef, Olaf Koeneman, and Marika Lekakou. 2009. Syntactic doubling and the structure of whchains. To appear in Journal of Linguistics.

Bech, Gunnar. 1955/57. Studien über das deutsche verbum infinitum. København: Det Kongelige Danske Akademie av Videnskaberne.

Beck, Sigrid. 1996. Wh-constructions and transparent logical form. Ph.D. dissertation, University of Tübingen.

Carlson, Greg. 1977. Reference to kinds in English, PhD Dissertation, University of Massachusetts.

Chomsky, Noam. 1995. The minimalist program. Cambridge, MA: The MIT Press.

De Haan, Ferdinand. 1997. The interaction of modality and negation: A typological study. New York: Garland.

De Swart, Henriëtte. 2000. Scope ambiguities with negative quantifiers. In Reference and anaphoric relations, ed. Klaus von Heusinger and Urs Egli, 109-132. Dordrecht/Boston/London: Kluwer Academic Publishers. 
Di Sciullo, Anna-Maria, and Edwin Williams. 1987. On the definition of word. Cambridge, MA: The MIT Press.

Fanselow, Gisbert, and Damir Cavar. 2001. Remarks on the economy of pronunciation. In Competition in syntax, ed. Gereon Müller and Wolfgang Sternefeldt, 107-150. Berlin: De Gruyter.

Fanselow, Gisbert, and Damir Cavar. 2002. Partial deletion. In Theoretical approaches to universals, ed. Artemis Alexiadou, 65-97. Amsterdam: Benjamins.

Fox, Danny. 1999. Economy and semantic interpretation. Cambridge, MA: The MIT Press.

Gajewski, Jon. 2007. Neg-raising and polarity. Linguistics and Philosophy 30: 289-328.

Geurts, Bart. 1996. On no. Journal of Semantics 13: 67-86.

Giorgi, Alessandra, and Massimiliano Pianesi. 1997. Tense and aspect: From semantics to morphosyntax. Oxford: Oxford Studies in Comparative Syntax.

Hackl, Martin. 2000. Comparative quantifiers. PhD dissertation, MIT.

Halle, Morris, and Alec Marantz. 1993. Distributed morphology and the pieces of inflection. In The view from Building 20, eds. Kenneth Hale and Samuel Jay Keyser, 111-176. Cambridge, MA: The MIT Press.

Heim, Irene. 2006. Little. In Proceedings of SALT 16, eds. Christopher Tancredi, Christopher, Kanazawa Makoto, Imani, Ikumi, and Koyomi Kusumoto. Ithaca, NY: Cornell Linguistic Circle, Ithaca.

Horn, L. 1989. A natural history of negation. Stanford: CSLI Publications.

Iatridou, Sabine, and Ivy Sichel. 2010. Negative DPs, A-movement, and scope diminishment. To appear in Linguistic Inquiry.

Jacobs, J. 1980. Lexical decomposition in Montague Grammar. Theoretical Linguistics 7: 121-136.

Klima, E. 1964. Negation in English. In The structure of language, ed. J. Fodor and J. Katz, 246-323. Englewood Cliffs: Prentice-Hall.

Kratzer, Angelika. 1995. Stage-level and individual-level predicates. In The generic book, ed. Greg Carlson and Francis Pelletier, 125-175. Chicago: University of Chicago Press.

Ladusaw, Bill. 1992. Expressing negation. In Proceedings of SALT 2, eds. Chris Barker, and David Dowty. Ithaca: Cornell Linguistic Circle.

Merchant, Jason. 2001. The syntax of silence. Oxford: Oxford University Press.

Müller, Gereon. 2007. A constraint on remnant movement. Natural Language \& Linguistic Theory 14: 355-407.

Neeleman, Ad, and Kriszta Szendröi. 2007. Radical pro drop and the morphology of pronouns. Linguistic Inquiry 38: 671-714.

Penka, Doris. 2002. Zur Semantik der negativen Indefinita im Deutchen. In Tübingen-Linguistik-Report 1.

Penka, Doris. 2007. Negative indefinites. PhD Thesis, Universität Tübingen.

Penka, Doris and Hedde Zeijlstra. 2005. Negative indefinites in Dutch and German. LingBuzz. http://ling. auf.net/lingBuzz/000192. Accessed 1 January 2009.

Penka, Doris, and Arnim von Stechow. 2001. Negative indefinita unter modalverben. In Modalität und Modalverben im Deutschen, Linguistische Berichte, Sonderheft 9, ed. Reimar Müller and Marga Reis, 263-286. Hamburg: Helmut Buske.

Rullmann, Hotze. 1995. Geen eenheid. Tabu 25: 194-197.

Weerman, Fred, and Jacqueline Evers-Vermeul. 2002. Pronouns and case. Lingua 112: 301-338.

Zanuttini, R. 1997. Negation and clausal structure: A comparative study of Romance languages. Oxford: Oxford University Press.

Zeijlstra, Hedde. 2008. On the syntactic flexibility of formal features. In The limits of syntax, ed. Theresa Biberauer, 143-174. Amsterdam: Benjamins.

Zeijlstra, Hedde. 2004. Sentential negation and negative concord. PhD dissertation, University of Amsterdam.

Zimmermann, Ede. 1993. On the proper treatment of opacity in certain verbs. Natural Language Semantics 1: 149-179. 